\section{REDEFINITION OF ARCHITECTURAL REPRESENTATION IN THE COMPUTATIONAL DESIGN ENVIRONMENT: NUMERIC REPRESENTATION}

\author{
Başak UÇAR
}

Received: 10.05.2010; Final Text: 20.04.2011

Keywords: architectural representation; computational design; orthographic set; numeric set.

1. This paper is a revised and up-dated summary of the M.Arch thesis of the author, Uçar (2006).

\section{INTRODUCTION}

The developments in the 20th century in technology and computer-aided communication means, as well as studies in mathematics, geometry and science have brought about significant changes in architecture as a consequence of its close relation with other disciplines (1). Changes in the formation, modification and transformation of data affected the architectural design practices directly or indirectly and altered the conception of space, its perception and visual expression in a radical way. Parallel to these developments, computational design tools and strategies such as parametric design, associative geometry, algorithmic procedures and scripting, which are already practiced in industries such as aerospace, automotive and shipbuilding propose the potential to alter the boundaries of architectural design and representation processes (Kolarevic, 2005). The use of mentioned strategies in architectural design processes influenced and blurred the relationships between the environment and the data, between the virtual and the real and also between the design ideas and their architectural representation. In this paper it is aimed to discuss the architectural representation process in the computational design environment and consider the radical shifts recognized in its re-definition subsequent to the ubiquitous practice of computational design tools and strategies.

In this challenging research and design practice, computers and computational design tools are not utilized only for the transfer, manipulation or printing of already conceptualized ideas (Terzidis, 2003). Instead, their use promotes the conception of design ideas, as well as their representation and manufacturing through the very same medium offered by these tools. (Kolarevic, 2000). It is argued in the paper that, when different phases of design process are associated to define a continuous one, representation of design ideas is seen to go beyond mere drafting or visualizing procedures, indicating a shift in the conventional architectural 
representation process. In this respect, the paper discusses the substitution of the orthographic set with the numeric set as an outcome of the extensive use of mathematical models in the computational design research and practice.

\section{DISSOLUTION OF THE ARCHITECTURAL REPRESENTATION PROCESS AND NUMERIC REPRESENTATION}

Recent design strategies facilitated by the advances in computer technologies, are mainly structured with parameters and relations, which define the mathematical model and accordingly the animations, virtual and augmented realities, 3D prints, and so on. Through the assimilation of these strategies, the architect becomes capable of defining and controlling the whole process through the same mathematical model that is active in all phases of the process from the initial phases on. In this approach, the decisions are all embedded in relations, which are stored as parametrically defined equations in the mathematical model (Kolarevic, 2000).

By expressing this network of relations the architect acquires the capacity to re examine and redefine them at any time. After these interventions, the mathematical model updates itself simultaneously without any extra workload in terms of redrawing or recalculation, since the same network of relations are used in the model that is experienced throughout the whole process. This formation also provides the numeric and visual representations of the newly defined conditions in parallel processing, since it is the same mathematical model that assists and enables the temporary visualization and representation of the design ideas. Accordingly, the architect becomes capable of experiencing the ever-changing representations of the relations, where the architectural representation process is conceptualized as a participant in all phases of the process. In order to define a homogenously diffused representation, the architect takes advantage of these strategies and assimilates the use of the mathematical model.

Considering the entire diffusion of architectural representation in all phases of the process it can be claimed that, there occurs a shift in its conceptualization where new possibilities and experimental grounds are proposed both for the architect and the design process. In this new paradigm, the notions of architectural design, which the architect has already been accustomed to, were revolutionized and departed from conventional techniques (Koutamanis, 2000). With this departure, it is not only referred to the replacement of the common use of paper and pencil with parameters, equations, and algorithms, but also to the use of computer as a design medium rather than a mere drafting tool. It is possible to argue that, until recently, the computers were used simply as drafting tools for representation that aid the architectural design process. However, with the assimilation of computational design strategies, the computers have gone beyond facilitating communication, drafting or visualizing and are conceptualized as being generative devices of the design process. In order to actively participate in the computational design environment, the conventional architectural design processes based on an orthographic set of drawings are now being supplanted by a numeric set that responds to the ever changing relations and parameters. Accordingly, the architectural representation process in general and the orthographic set in particular, which can be interpreted not only as an expression of design ideas and 
architectural interpretations but also as a language making use of verbal, visual and numeric expressions, can be asserted to witness a radical shift.

Translation from an orthographic set to a numerical set requires the assimilation of numeric definitions in all phases of the design process, where it also implies a shift from visual to non-visual modes of conception, to what can be called a non-representative process. Conceptually and technically made possible with the advances in current practice, this nonrepresentative process can be considered as a strategy and challenge to the conventional design processes. Thinking through the tools of a numeric set such as control parameters and associative relations, participating in the whole process as agents provoking the generation, evolution and transformation of design ideas, allows deciphering how this strategy entails new experiences.

One way of attaining the shift to a non-representative medium is to perform a parametric design approach through associative geometry or algorithmic procedures, which enable to embed the representation of design ideas within the relations and equations used. Parametric design, preserving the definitions of shapes in parameterized representations, has the potential of defining a new approach both in architectural design and in architectural representation. Rather than specifying form through fixed and non-relative definitions, parameters that are relative to each other are being used. As a consequence, form inherits not a unique definition but becomes open to modifications and redefinitions. For this reason, through the parametric model defined, the architect becomes equipped to describe complex forms under topological transformations.

One of the approaches that assist this shift is the use of associative geometry, where all elements are geometrically dependent on each other. In this approach, the architect deals with a flexible and responsive model transmitting and assimilating any change in the model or parameters automatically (Burry, 1999). The model, through its unique definition, evolves and updates its elements to the newly defined conditions at any instance of the process. Therefore, through the mutually linked elements having dependency relations in-between, it becomes possible to define a flexible, modifiable and deformable mathematical model "representing not only one design solution, but a whole set of potential variation" (Aish, 1992). Experiencing this potential, the architect becomes capable working with sets of formal definitions and their numeric and non-visual representations in parallel processing which can be visualized whenever needed.

A different means of assisting parametric design, where the entities are connected to each other is the use of algorithmic procedures. In these procedures, the architect may either prefer to use the software programming inherited within the computer interface or go beyond the rules already identified within these programs where s/he can then define his/ her own procedure and provide the script of the process. Despite the extensive use of algorithms and algorithmic procedures in computer programming, their employment in architectural design appears principally after the introduction of new computational design strategies, marking a radical shift in the practice. In this process, algorithmic description of the geometry and the procedure is enabled through a network of mathematical models where a set of parametric variables and regulations are identified according to a generic key (Terzidis, 2003). 
Although, working with an adaptable mathematical model is a common virtue that can be traced also in other parametric approaches, in algorithmic procedures this model is accompanied by a script. Through modifying the internal structure, that is, the script, the whole process can be manipulated and a new set of possibilities can be defined. As a consequence, every new execution of the algorithm may give rise to the evolution of design solutions tracked by new outcomes. Concentrating more on the relations and the script in order to define new outcomes can shift the focus from formal to numeric descriptions and initiate new formal repertoires where the architect can augment the architectural design process as well as his/her perceptual field (Mennan, 2005a).

Consequently, algorithmic procedures and scripting techniques define a new design environment which alters both the already accustomed design process and the role of the architect. The architect, in this newly defined medium, needs to comprehend the algorithmic procedure not as a representational tool for visualization and form generation, but instead as a generative tool responding to every phase from form-generation to manufacturing (Kolarevic, 2000). It is mainly the numeric definitions of the relations that is experienced through the process which are not accompanied by their visual correspondences. By way of attention placed on the algorithm and accordingly on the relations, the visual representations are by-passed and the architect works with the numeric ones. However, when demanded the visual representation(s) of the current situation can be provided since it is maintained non-visually throughout the entire process.

In parametric procedures, either associative or algorithmic, where the same medium is used for the conception, generation and representation of design ideas, different phases of the design process are connected to each other. This formation not only enables the compatibility of the model with the newly defined conditions, but also the uninterrupted definition of the phases and their interference into each other. Considering this intricate relationship it may be observed that it becomes hard to define a distinct phase for the representation of design ideas.

Since different phases of a design process guided by computational design tools and strategies are connected to each other through relations and equations that enable its responsiveness to the modifications in the model, it may be asserted that the clear distinction between different phases of design process has blurred or even totally disappeared. Ability to define the files and their numeric representations at the very beginning of the design process, which will be used at all phases, underlines the continuation between them. As a consequence of this continuation, when the architect introduces a change in the model even in the manufacturing phase, all other files used in other phases are updated and redefined automatically. This condition indicates a non-linear design process where the architect can have forward and backward moves in-between different phases of the process.

\section{NON-VISUAL REPRESENTATION AND CONSCIOUS DELAY OF VISUAL REPRESENTATION}

In the light of aforementioned changes, architectural design and representation processes are altered in order to attain the desired and proposed flexibility and indeterminism of the constantly evolving 
Figure 1. Visual and Numeric representation of the code scripted by Deniz Okten, Mert Ayaroğlu and Başak Uçar as part of the graduate elective studio ARCH 719 Computational Design Research Lab (CoDeReL), at METU Department of Architecture in Spring 2005, that reconsidered the formal, perceptual and conceptual discussions of housing research and Dom-ino House with algorithmic and scripting procedures. Critics for Spring 2005: Assoc. Prof. Dr. Zeynep Mennan, Assoc. Prof. Dr. Mine Özkâr, Fuat Etker. Mel scripting: Emre Erkmen.
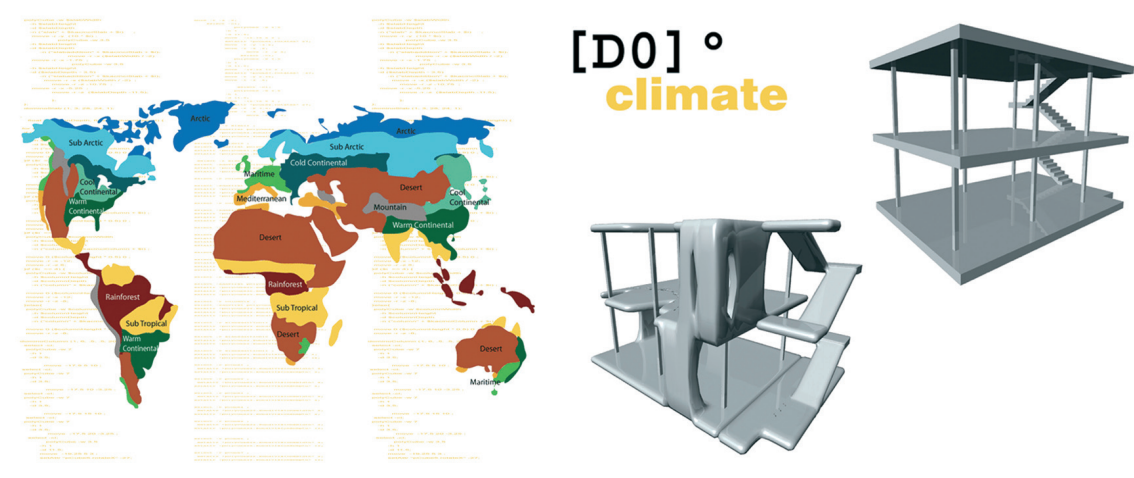

procedures. It is possible to trace that, in this new design environment more attention is placed on the process where the dependency relations, equations and parameters are defined rather than formal concerns. Along with that, expression of design ideas loses its significance since the "endproduct" of the process is considered as a momentary outcome that is not the final and absolute solution but instead a frozen state of the network of relations. However, regardless of this shift in the interest, the entire process is still accompanied by the uninterrupted definition of the non-visual but numeric representations.

Although the architect can refer to these momentary representations whenever needed, it can be noted that this appetite is delayed consciously as much as possible. The conscious delay of visual representation directs the architect's attention more on the process and relations and therefore gives rise to experimental studies. Enabled with the strategies and tools used, the architect can make numerous trials and come up with sets of solutions either predicted or unpredicted. Taking the advantage of this delay, s/ he acquires the opportunity to generate multiple relations and solutions of which visual representations are kept hidden in the numeric definitions until it is deliberately sought. Zeynep Mennan asserts that focusing on the numeric expressions and relations rather than form brings forth an environment liberated from the visual constraints, forces the formal repertoire of the architect and at the same time enables the experience of new design ideas: Hence, this condition can be argued to provide the architect with the opportunity of extending the boundaries of his/ her visual repertoire (Mennan, 2006). Therefore, substitution of visual representation with the momentary representations and suspending the visual representation can be conceived as proposing a detachment from the visual constraints and formal images of our perceptual field and a change in the conception of architectural representation process (Mennan, 2005a).

Delay in visual expression is considered as facilitating the desired indeterminacy and unpredictability of the process which is never concluded; it is defined by Ali Rahim as "systemic delay" (Rahim, 2000). By "systematic delay" it is referred to the "temporal interstice of conceptual development between initial idea and its material form" and claimed that this interstice can introduce generous opportunities for the architect (Rahim, 2000). According to Rahim, the process that is based upon an evolving structure, can take the advantage of such 'systemic delay' and maximize the potential of indeterminacy with the aid of computational design tools and strategies (Rahim, 2000). Through exploiting the potentials of this delay, the architect acquires the opportunity to generate 
multiple relations and re-evaluate the design, manufacturing and representation processes, which are in constant evolution. However, since the systemic delay of visual representation conflicts with the architect's conventional training, where $\mathrm{s} /$ he works with the visual representation of the design ideas throughout the design process, their delay or non-visual representation of design ideas may lead to a 'perceptual deception' and 'disorientation.' (Mennan, 2005a).

An example of this shift was experienced in a research project developed during the spring term of 2005 at the computational design research lab (CoDeReL) at the Middle East Technical University in Ankara. The research project titled as "Algorithmic Research into Housing Populations: Scripting [D]n Replication of a Memetic Code" undertakes an algorithmic approach and focuses on Le Corbusier's Dom-ino House with an aim of producing non-standardized housing (Dom-ino) populations. Working within the computational medium, it is intended to develop an algorithm that first initiates the original Dom-ino House [D]0 and subsequently gives way to differentiated populations of the Dom-ino House [D]n. Therefore, through using MayaMel Scripting interface, a script was developed that defines the [D]n populations through the modification of the variables. However, it is mainly concentrated on the definition of relations used in the script rather than their formal outcomes and their visualization were delayed intentionally. Experimenting in the non-visual medium of the script enabled the departure from the visual and formal properties of the Domino House (Mennan, 2006). Therefore, the script is used as a design strategy to interpret the interface between the visual and the non-visual/numerical and liberate the design ideas from these visual and formal properties.

In order to experiment in this medium and intentionally delay visual representation while dealing with the non-visual/numeric representations of the initial outcomes, it is proposed to question the ubiquity and the a-contextuality of the Dom-ino House. In the proposed experiment the Dom-ino House's adaptability in various regional and climatic environments was tested. Integrating local inputs (temperature, luminance, climatic adaptation) into the original script, this experiment produced



Figure 2. As a part of ARCH 719 Computational Design Research Lab (CoDeReL) course a script was developed that provides non-visual/numeric representations of relations and also visual outcomes whenever needed. 


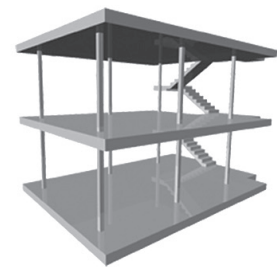

[D] Domino

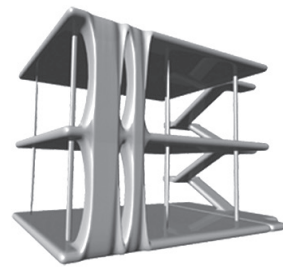

Dacca

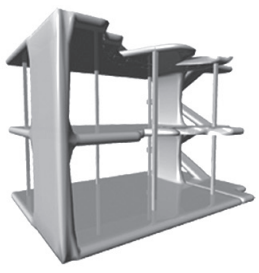

London



Alaska



Svalbard
Figure 3. Series of end-products were calculated for different geographic locations through changing the parameters used in the script (such as climatic region, geographic location, sun angle and average temperature). new formal populations. These populations were derived through changing the variables put forward in the initial algorithm. Updating the variables indicating the local inputs of the selected geographic location, the formal outcome of the process altered of which visualization was grasped whenever needed. However, in order to experience the nonvisuality of the process it is intentionally aimed to deal with non-visual / numeric representations embedded in the script and the whole population was visualized altogether at the end of the process. Through this approach it became possible to test the diversity in the formal properties of the outcomes differing according to the changes in the local inputs. Accordingly, the project experienced the non-visual medium of scripting and the shift from visual to numeric representation. During the process, the visual representation of different outcomes were presented through temporary visualizations and also through the script, which indicated the shift in the architectural representation process; the shift from visual to numeric representation.

Conventional architectural representation tools and processes seem to be in need of redefinition in order to make use of the potentials and the dynamics of the newly defined design environment. This situation further underlines the necessity of the adaptation of the architect to the shift from the visual to the non-visual and also to the strategies that dissolve the architectural representation within the whole process while eliminating the borders between different phases. Working through parametric models as well as numerical and non-visual representations calls for the architects' competence in the aforementioned tools and strategies in order to define and manage the complex computational programming operations and the non-visual design process. If the architect was trained with conventional architectural design tools and strategies, $\mathrm{s} /$ he may face certain difficulties in defining and controlling these computational processes, hence may not take the whole advantage of this newly defined design environment. In order to overcome this problem and take advantage of this environment, the architect needs to be equipped with necessary information in order to shift his/her perceptive and mental set, and get accustomed to using the numeric set for defining and scripting the relations used at all phases of the process instead of the familiar orthographic set.

\section{CONCLUSION}

This paper argued that, subsequent to the introduction of computational design tools and strategies, which altered the conventional architectural design approach, and opened up new grounds for the generation and experimentation of design ideas, ways of representing design ideas 
have undergone significant changes. It is argued that the architectural representation process, acting as a critical design and communication tool for centuries, experienced a conceptual shift under the influence of computational design strategies and practices. This shift guided by computational design tools and strategies, is asserted to give rise to new experiences, hence to new experimental studies for the architect. Architects' work with parametric models, that can be used in all phases of the process and that are responsive to modifications, brings about the use of a numeric set instead of an orthographic set, where the architectural representation process is eroded numerically within the phases of the process. This experience is exemplified with a research exercise carried at the computational design research lab (CoDeReL) at the Middle East Technical University. Radical shifts in the architectural design and representation processes parallel to the use of computational design strategies in architectural practice bring together the need to redefine the role and responsibilities of the architect, of architectural representation and thus, of the architectural design process.

\section{REFERENCES}

AISH, R. (1992) Computer-aided Design Software to Augment the Creation of Form, Computers in Architecture: Tools for Design, ed. By F. Penz, Harlow, UK.

BURRY, M. (1999) Paramorph: Anti-accident Methodologies, AD: Hypersurface Architecture II (69: 9-10) 78-83.

CACHE, B. (1999) Plea for Euclid, Any (24) 54-9.

FOSTER and PARTNERS. (2004) Swiss Re, Digital Fabricators, The Association for Computer Aided Design in Architecture, University of Toronto, Faculty of Architecture Landscape and Design. Available from:

http:// www.philipbeesleyarchitect.com/publications / ACADIA04DigiFab/DigiFab.pdf. [Accessed: 5 March 2010]

KOLAREVIC, B. (2000) Digital Morphogenesis and Computational Architectures,

first published in the Proceedings of the 4 th Conference of Congreso Iberoamericano de Grafica Digital (Rio de Janeiro, 2000). Available from: http: / / cumincades.scix.net/data/works/att/fbc9.content.pdf [Accessed: 3 May 2010]

KOLAREVIC, B. (2004) Towards Non-Linearity and Indeterminacy in Design, Cognition and Computation in Digital Design. Available from: http://www.technion.ac.il/ rivkao/topics/publications / AID\%20Workshop.pdf [Accessed: 20 April 2010]

KOLAREVIC, B. (20005) Digital Praxis: From Digital to Material, ERA (21:4) 50-54.

KOUTAMANIS, A. (2000) Digital Architectural Visualization, Automation in Construction (9-4) 347-60.

MENNAN, Z. (2005a) From Number to Meaning: Prospects for a Quantitative Hermeneutics at İstiklal, Architecture in Turkey Around 2000: Issues in Discourse and Practice, ed. by T. Korkmaz, Chamber of Architects of Turkey, Ankara; 121-32. 
Alınd1: 10.05.2010, Son Metin: 20.04.2011 Anahtar Sözcükler: mimari temsil; sayısal tasarım; ortografik set; sayısal set.
MENNAN, Z. (2005b) Non Standard Mimarlıklar: Bir Serginin Ardından, Mimarlik (321) 37-41.

MENNAN, Z. (2006) Non Standardization Through Non-Visualization: Scripting the Dom-Ino House, The Architecture Co-Laboratory: GameSetandMatch II, International Conference On Computer Games, Advanced Geometries and Digital Technologies, Delft University of Technology, Faculty of Architecture, The Netherlands.

RAHIM, A. (2000) Systemic Delay: Breaking the Mold, AD: Contemporary Processes in Architecture (70:3) 6-8.

TERZIDIS, K. (2003) Expressive Form: A Conceptual Approach to Computational Design, Spon Press, New York.

UÇAR, B. (2006) An Assessment of the Architectural Representation Process within the Computational Design Environment, B.Arch. Thesis, METU Department of Architecture, supervised by Prof. Dr. Zeynep Mennan.

\section{MIMMARİ TEMSİL SÜRECINIIN SAYISAL TASARIM ORTAMINDA YENIDEN TANIMLANMASI: SAYISAL TEMSİL}

Bu makalede, 20. yüzyılda bilim, matematik, geometri, bilgisayar destekli iletişim ve tasarım alanlarındaki gelişmelerin doğrudan ya da dolaylı olarak mimari tasarım ve temsil süreçlerinde tanımlamış olduğu sıçramalar incelemiştir. Makale kapsamında, havacılık, otomotiv veya gemi sanayisi gibi alanlarda kullanılmakta olan sayısal tasarım araçlarının ve stratejilerinin mimari tasarım ve temsil süreçlerine dahil edilmesi bu süreçleri değiştiren ve dönüştüren bir gelişme olarak ele alınmıştır. Bu bağlamda, sadece tasarım fikirlerinin ve mimari çözümlerin ifadesi olarak değil, sözlü, görsel ve sayısal ifade biçimlerini kullanan bir dil olarak da yorumlanabilen mimari temsilin ve ortografik çizimin, sayısal tasarım ve üretim süreçlerindeki gelişmelere paralel olarak yeni bir sıçramaya tanıklık ettiği belirtilmiştir. Bununla birlikte, sözkonusu sayısal tasarım araç ve yöntemlerinin mimari tasarım süreçlerinde kullanılmasının tasarım fikirleri ve onların mimari temsili arasındaki ilişkileri bulanıklaştırdığı vurgulanmış ve görsel olmayan sayısal temsilin bir strateji olarak benimsenmesi ele alınmıştır.

BAŞAK UÇAR; B.Arch, M.Arch. Received her B.Arch (2003) and M.Arch (2006) degrees from the Department of Architecture at METU. Currently a member of METU Department of Architecture as a part-time instructor, where she worked as a research assistant from 2006 to 2011. basakucar@gmail.com 